\title{
Survey of the Relationship Between Extroversion and Transition in Cigarette and Hookah Smoking Stages in High School Students in Tabriz: A Longitudinal Study
}

\section{Hadi Pashapour}

Tabriz University of Medical Sciences

\section{Asghar Mohammadpoorasl}

Tabriz University of Medical Sciences

Hossein Dadashzadeh

Tabriz University of Medical Sciences

Saeid Mousavi ( $\square$ musavis@tbzmed.ac.ir)

Tabriz University of Medical Sciences https://orcid.org/0000-0001-7424-5770

\section{Research}

Keywords: Adolescent students, Stages of smoking, Hookah smoking, Extroversion, Cigarette smoking

Posted Date: June 15th, 2021

DOl: https://doi.org/10.21203/rs.3.rs-589062/v1

License: (c) (i) This work is licensed under a Creative Commons Attribution 4.0 International License.

Read Full License 


\section{Abstract}

Background: Smoking is a major public health problem that specifically affects the adolescent population health and future. This study aimed to investigate the relationship between extroversion and transition in cigarette and hookah smoking stages in high school students in Tabriz city.

Methods: A sample of 2256 high school students aged 15-16 years old in Tabriz was included in the study. Demographic characteristics, cigarette, and hookah smoking status, and Eysenck's extroversion questionnaires were completed by all students in the selected schools. Eight months later, cigarette and hookah smoking status was assessed again to determine transition in smoking stages. Marginal Homogeneity test was used to compare the smoking status at the beginning and eight months later. The Generalized Estimating Equation method with the ordinal link was applied to estimate the effect of extroversion on transition in smoking stages.

Results: The mean (SD) age of the students participating in the study was 15.5 (0.5) years old. Marginal homogeneity test results show that, in general, transmission in the stages of both cigarette and hookah smoking in eight months was significant in students (P-Value $<0.0001)$. Extrovert personality had a significant positive effect on the transition from lower stages to higher cigarette and hookah smoking stages according to GEE with ordinal link $(P<0.0001)$. In cigarette and hookah smoking, extrovert persons transited to higher stages 1.56 and 1.68 times than introvert persons.

Conclusions: Being an extrovert person had a significant effect in the transitioning to higher stages of smoking cigarettes and hookah.

\section{Background}

In the field of smoking, adolescence is an important period that poses a great challenge in the field of control and prevention of smoking (1). Most international studies show that about $85 \%$ to $90 \%$ of smokers start smoking before the age of 20 . Smoking in adolescence also predicts its use in adulthood $(2,3)$. Smoking just a few cigarettes in adolescence increases the risk of smoking 16 times in adulthood (2).

In addition to cigarette smoking as the most common type of tobacco use (4), using hookah in many parts of the world has become the first or second most common method of smoking among adolescents (5). Exposure to nicotine by using a hookah is addictive (6), and evidence suggests that young people who like hookah smoking are more likely to start smoking (7). This illustrates that risk factors for cigarette and hookah use in young people may be common (8).

Cigarette and hookah smoking in adolescents not only increases the risk of many diseases in the short term such as respiratory disease, asthma, and decreased lung function, but also increases the risk of serious chronic diseases such as lung cancer, heart disease, and stroke $(9,10)$. If the current trend of 
smoking continues, 250 million children and adolescents who continue to smoke until adulthood will die from health problems related to smoking (11).

About 80 percent of the 1.1 billion smokers worldwide live in low- and middle-income countries, where the burden of tobacco-related illness and death is high (12). Smoking has increased in most developing countries over the past 20 years. The World Health Organization has described smoking as an epidemic in developing countries $(13,14)$. Between 1990 and 2009, smoking in Western Europe fell by almost 26 percent, while smoking increased by about 60 percent in Africa and the Middle East (15). Although most tobacco control efforts focus on preventing smoking, 80,000 to 100,000 adolescents worldwide start smoking every day, and almost half of them become regular smokers (16). Epidemiological data from countries that have monitored hookah use have drawn alarming trends. In the Middle East, hookah has quickly replaced cigarettes as the most popular method of tobacco use among young people, and in several other parts of the world, it has become second only after cigarette smoking (17).

About $31 \%$ of men and $11 \%$ of women worldwide smoke regularly (18). The prevalence of smoking among adolescents in European countries is very high, from 2\% (Finland and Norway) to $25.7 \%$ (Ukraine) among boys and $3 \%$ (Finland and Norway) to $26.3 \%$ (Italy) for girls, respectively. (19). In the Eastern Mediterranean (EMR), the percentage of adolescent smokers is increasing. Findings from the Global Youth Survey show that $2 \%$ of girls and $7 \%$ of boys in EMR are smokers (20). Particularly in the Middle East, several epidemiological surveys have demonstrated the dramatic popularity of hookah among young people $(21,22)$. In a large study of 100,000 students at 152 universities in the United States, the prevalence of regular hookah use was 8.4 percent (23). A multi-country study including a sample of school children aged 13-15 in several countries of the Arabian Peninsula (Bahrain, Oman, Qatar, Saudi Arabia, UAE, Kuwait, and Yemen) showed that the prevalence of hookah was from $9 \%$ to $15 \%$ and was more than the prevalence of cigarette smoking (24).

Iran has one of the youngest population indices in the world among developing countries (25). Despite many efforts to reduce or prevent smoking among Iranian youth, this habit is still common and has even been shown to be growing (26). A list of countries with a traditional prevalence of tobacco use among people aged 15 and over was published by the World Health Organization in 2016, with Iran ranking 84th with an $11.1 \%$ prevalence (27). A cross-sectional study conducted in Tehran during 2014-2015 with a sample number of 1830 citizens over 15 years of age, the prevalence of hookah smoking was $17.6 \%$. The prevalence of hookah use in men was significantly higher than in women $(24.2 \%$ vs. $11.3 \%)(28)$. In another study, 1524 students aged 14-18 (764 boys and 760 girls) were selected. The prevalence of smoking was $9.5 \%$ and hookah was $10.4 \%$. About 3.7 percent of teens used both cigarettes and hookahs, and 16 percent used at least one of them. In boys compared to girls, the prevalence of smoking $(13.1 \%$ vs. $6.4 \%)$ and hookah (13.7\% vs. $7.1 \%)$ was higher (29).

Adolescence is an important stage for the onset of high-risk behaviors due to adolescents' lack of understanding of the risky consequences of their behaviors (30). Smoking is a complex behavior that is associated with psychosocial, economic-political, and biochemical factors and cannot be a single reason 
to start smoking in adolescents (31). Many researchers have considered smoking behavior in adolescents as a development in a series of stages. Due to the participation of various disciplines such as psychology, epidemiology, behavioral sciences, etc. in research on smoking, there are various definitions of the stages of smoking. Although starting and continuing to smoke is inherently a continuous process, hundreds of studies have attempted to break this process down into steps that include primary and secondary prevention. A study in 1980 suggested that smoking has a complex course and takes several steps for a person to become a smoker (32). Smoking behavior among adolescents can include several stages of development: pre-contemplation, contemplation, trial or initiation, experimentation, regular smoking, and addiction to nicotine or daily smoking (33).

Relatively stable personality traits are specific characteristics and main indicators of behavior (34). Many studies have shown that personality is one of the main risk factors associated with abusive behaviors (35), so it is vital to examine the extent to which personality affects negative health behaviors (36). Researchers have suggested that individual, familial, and social risk factors may lead to nicotine dependence. Among these factors, personality traits that make a person sensitive to nicotine can play an important role in this process. Thus, psychological factors can play a decisive role in determining who starts smoking, who continues, and who quits smoking (37).

One of the main personality traits is extroversion and introversion. Extroversion and introversion are the main dimensions of human personality. These terms were widely popularized by Carl Young (1920) (38). Extroversion is manifested in the tendency to go out, talkativeness, and energetic behavior, while introversion is more pronounced in individual behavior and restraint (39). The study of personality traits and smoking has been started in the 1970s, and almost from the very beginning, extroversion has been considered as one of the main factors (40). Most studies that have examined extroversion through smoking have either examined this association in adults $(41,42)$, or only in developed countries $(34,42,43)$, or the form of other aspects of personality traits $(34,36,41,43)$. Also, the results obtained from previous studies are contradictory, so that some of these studies have found a relationship between these factors $(36,44,45)$ and others have not $(46,47)$. Also, no study has been found to measure the effect of extroversion by going through the stages of smoking and hookah. Therefore, considering that it has been proven that this relationship needs to be studied in different societies, including developing societies such as Iran (41) and also the need to study this relationship as a longitudinal study with an approach to smoking and hookah use in adolescents, (To increase the accuracy of primary and secondary prevention), the present study was conducted to assess the effect of personality type (extroversion/introversion) in transition between smoking stages and use the results in smoking prevention programs.

\section{Methods}

The study was conducted between February to October 2017 in a sample of students aged 15-16 years old in Tabriz, the capital city of East Azerbaijan province in the northwest of Iran. Samples were selected by the multi-stage cluster sampling method. The first clusters were schools; 21 high schools were 
randomly selected from all high schools in the Tabriz. Second clusters were classes; considering the type of high schools (private/state), gender of students, and required sample size, 91 classes were chosen randomly and all students in the classes were included in the study. The total number of students who participated in the study was 2312 .

After a full explanation of the purpose of the study, informed consent was obtained from students. Then, the students completed their questionnaire without a name in the class. The questionnaire included questions about cigarette and hookah smoking, extroversion scale, and other demographic characteristics.

Extroversion was measured using the Eysenck Personality Questionnaire(48) for the age group above 15 years old. The section associated with extroversion and introversion of this questionnaire contained 24 questions, where the answer to each question was a "Yes" or "No", and each of the questions received a score of 1 or 0 according to the guideline on how to use the questionnaire. Therefore, the range of scores was from 0 to 24 . Higher scores showing higher extroversion personality. In a psychometric study of this questionnaire in Iran, Pearson's correlation coefficient (reliability index) and Cronbach's alpha (internal consistency) were 0.88 and 0.79 , respectively (49).

Cigarette smoking was assessed by a valid algorithm for cigarette smoking status in adolescents (50). According to recent studies $(26,51)$, the cigarette smoking status in this study was considered as the following three stages:

1. Never smoked: Students who have never smoked;

2. Experimenter smokers: Students who have experimented with cigarette smoking and have smoked less than 100 cigarettes;

3. Regular smokers: Students who have smoked 100 cigarettes or more during their life.

Hookah's use was assessed using a multiple-choice question with the answers of "Never smoked", "Just experimented", "Sometimes", "At least once a month", and "At least once a week". Then, the students were placed with regard to their answer in one of the three following groups:

1. Never smoked: Students who have never smoked hookah (even a puff);

2. Experimenter smokers: Students who have experimented the hookah or smoked hookah occasionally (Just experimenter, Sometimes);

3. Regular hookah user: Students who use hookah at least once a month.

To facilitate the follow-up of students in the second phase of the study, which took place eight months later, each student was assigned a special code that was recorded at the top of the form in both phases of the study. In the second phase, students completed another questionnaire that included cigarette and hookah smoking status. 
Cross-tabulating the status of cigarette and hookah smoking in the first and second phases of the study will show the amount of transition between smoking stages during eight months. The Marginal Homogeneity test was used to compare the smoking status in the beginning and eight months later among the student. Also, Generalized Estimating Equation with ordinal logit link was used to assess the effect of extroversion in transition between smoking stages. The analysis was done by R 3.6.2.

\section{Results}

2312 students entered the study at the first phase. 2256 students had completed the questionnaires correctly. From 2256 students participating in the study at the first phase, 1836 were followed up and 420 students were excluded from the study for any reason (Students change school in the second stage, absence from class in the second stage, and also, the days of completing the questionnaire coincided with the beginning of the camps and tours organized by the schools). The mean (standard deviation) age of the students who participated in the study was $15.5(0.5)$ years old. $46.7 \%$ of students were boys and $53.3 \%$ were girls. Also, $22 \%$ of them were introverts and $78 \%$ were extrovert persons. The frequency distribution of personality type was not different with respect to gender, $77 \%$ of males and $78 \%$ of female students were extroverts $(=1.12, P=0.29)$. Count $(\%)$ of transition between stages are reported for introvert, extroverts, and all students in Table 1. Looking at Table 1, transitions occurred in both personality types. All transitions occurred to higher stages. All of the off-diagonal elements in the lower the triangular of transition matrix were zero. $\mathrm{MH}$ test compares the off-diagonal counts in transition matrix for introvert, extroverts, and all students.

The result of the $\mathrm{MH}$ test was reported in the last column of Table 1. In all categories of personality in both cigarette and hookah smoking $\mathrm{MH}$ test was significant $(\mathrm{P}<0.001)$. The transitions that occurred in the smoking stages during eight months were significantly different from the beginning of the study. Also, $\mathrm{MH}$ test showed that in both male and female students transition in smoking stages in eight months was significant $(P<0.001)$.

The marginal distribution in Table 1 shows the frequency of smoking stages in the first and second phases (rows and columns with total counts). In all transition matrixes, the percentage of never smokers decreased in second phase and the percentage of the experimenter and regular smokers has increased.

Generalized Estimating Equation with cumulative ordinal logit link (in ascending order) was used to estimate the effect of personality type (Extrovert/ Introvert) and gender in transition between smoking stages in both cigarette and hookah use during the period from the first to second phase. The result of fitting the GEE model is reported in Table 2. According to the results, being extrovert had a significant positive effect on the transition from lower stages to higher stages in cigarette and hookah smoking $(P<0.0001)$. In cigarette smoking extrovert people tend to transit to higher stage $1.56\left(\mathrm{e}^{0.448}\right)$ times compared to introvert persons. The effect was $1.68\left(\mathrm{e}^{0.519}\right)$ in hookah smoking. Also, in cigarette and hookah smoking, male students transited to higher stages $2.51\left(\mathrm{e}^{0.922}\right), 1.93\left(\mathrm{e}^{0.661}\right)$ times than female students, respectively. 


\section{Discussion}

This study aimed to investigate the relationship between personality type (extrovert/introvert) and transition in cigarette and hookah smoking stages in high school students (15-16 years old) in Tabriz. The study was done in eight months. The results showed that there was a significant relationship between personality type and transition in smoking stages in both cigarette and hookah use. All transitions occurred to higher stages. The transitions investigated in extrovert and introvert persons separately. In both cases, transitions were to higher stages and were significantly different from the first phase of the study. The transitions in extrovert persons were more frequent than introvert persons. The GEE method revealed that extrovert person tends to transit to higher stages approximately 1.5 times than introvert persons.

According to the results of this study, the rate of cigarette and hookah smoking in extrovert students was higher than in introverts. A possible justification for this could be that introverts smoke cigarettes and hookah at older ages than extroverts, which suggests the need for further investigation.

Transition in the stages of smoking is higher in boys than girls, which is important. As shown in a previous study, gender is influential in the relationship between personality traits and smoking (52). In this study, the personality type had a significant effect on the smoking stages transition adjusting for gender.

In developing countries that were able to decline the trend of tobacco consumption, the relationship between personality type (extrovert/introvert) and tobacco consumption is weaker than in societies that were not successful in this issue (53-55). Especially hookah consumption in these countries is increasing rapidly and exceeded the amount of cigarette smoking and has become the first method of smoking, mainly in teenagers and young adults $(5,17)$. The result of this study also showed that the amount of smoking during eight months has increased considerably.

Extroverts are more likely to seek excitement and communication with others in the community, and as a result of this desire, they may be more likely than introverts to engage in risky behaviors, including smoking (56-57). This could be one of the reasons for the high transition in smoking stages in students subject to the current study.

There is a discrepancy in the results of studies about the relation between extroversion and smoking, some studies state positive relation (36,44-45), some others state there is no significant relationship (4647). Various reasons have been cited for this discrepancy. Older studies often found a significant relationship. But later studies did not achieve the same results. Eysenck states two reasons for this contradiction. First, the extroversion scale used in the earliest studies erroneously included sociability and impulsiveness. Later, when fluidity was added to Eysenck's theory as the main personality dimension, most stimulus items (extroversion impulsiveness items) were assigned to the psychoticism scale, resulting in recent studies failing to establish a positive relationship between extroversion and smoking behavior as before. The second reason proposed by Eysenck is that significant changes in social attitudes toward smoking acceptance have occurred in recent years, especially among men. As a result, 
men are less likely to be seduced into smoking by peer groups and friends. According to Eysenck, "Today, smoking behavior in society is more distasteful than ever before, and extroversion and smoking may be socially excluded, thereby reducing the expected correlation" (40). However, this study indicates the possible impact of this personality trait on the rate of smoking in adolescent students.

Buczkowski et al. (58) have recently shown that there is a link between extroversion and the onset and continuation of smoking. Compared to introverts, extroverts are more likely to be influenced by environmental factors that affect smoking, and these factors change their attitudes toward smoking more quickly. This aspect of extroversion could affect extrovert students who were smoked to transit to higher smoking stages than introvert persons. Given the importance of prevention in the field of smoking in adolescents and young people and also the very valuable role of school-based programs in prevention (64-68), the result of this study could be used in defining prevention programs for adolescent students in Iran.

Planning a study with more samples, a wider age group, and a longer follow-up with several time measurements could help to understand the trend of transition during the time and to obtain more information about the effect of personality type on the smoking status over time.

The students who participated in this study were limited to 15-16 year-old ages, which can limit the generalizability of the results to other age groups.

\section{Conclusion}

A significant transition in smoking during the eight-month interval between the first and second phases occurred in both cigarette and hookah smoking stages. All transitions were to higher stages in smoking. The personality type (extrovert/introvert) had a significant effect in transition to higher stages so that extrovert persons transited to higher stages considerably more than introvert persons. In designing cognitive programs to prevent people from smoking or to quit smoking, considering this dimension of personality trait can help in the program's effectiveness.

\section{Abbreviations}

MH: Marginal Homogeneity

GEE: Generalized Estimating Equation

\section{Declarations}

\section{Ethics approval and consent to participate:}

The plan of study and questionnaire was approved by the Ethics Committee of Tabriz University of Medical Sciences (Ethical code: IR.TBZMED.REC.1396.990) and the Research Committee of Education 
Organization of East Azerbaijan Province.

\section{Consent for publication:}

There was no issue on consent for publication in this study.

\section{Availability of data and materials:}

The datasets used and/or analyzed during the current study are available from the corresponding author on reasonable request.

\section{Competing interests:}

The authors declare that there is no conflict of interests.

\section{Funding:}

This study was supported by vice-chancellor of research at Tabriz University of Medical Sciences

\section{Authors' contributions:}

Hadi Pashapour: Data acquisition and writing the manuscript.

Asghar Mohammadpoorasl: Design and management of the study and writing the manuscript.

Hossein Dadashzadeh: Consulting about the behavioral issues in the study and writing manuscript.

Saeid Mousavi: Design of the study, data analysis and inferences and writing the manuscript.

\section{Acknowledgements:}

The authors would like to thank vice-chancellor of research at Tabriz University of Medical Sciences for supporting this study financially. Also we appreciate the Educational Office of Tabriz, the management team of schools, teachers, and all the participant students who cooperated with the research team in all steps of the study.

\section{References}

1. Mackay J, Eriksen M, Shafey O. The Tobacco Atlas. American Cancer Society. Atlanta, Georgia, USA. 2006.

2. Mohammadpoor Asl A, Fakhari A, Rostami F, Pourafkary N. Cigarette smoking among Iranian adolescents. Iranian Journal of Psychiatry Behavioral Sciences. 2007;1(1):30-5.

3. Taioli E, Wynder EL. Effect of the age at which smoking begins on frequency of smoking in adulthood. N Engl J Med. 1991;325(13):968-9.

4. Wigand JS. Additives, cigarette design and tobacco product regulation. A Report to WHO. 2006. 
5. Maziak W, Taleb ZB, Bahelah R, Islam F, Jaber R, Auf R, et al. The global epidemiology of waterpipe smoking. Tobacco control. 2015;24(Suppl 1):i3-12.

6. Aboaziza E, Eissenberg T. Waterpipe tobacco smoking: what is the evidence that it supports nicotine/tobacco dependence? Tobacco control. 2015;24(Suppl 1):i44-53.

7. Watkins SL, Glantz SA, Chaffee BW. Association of noncigarette tobacco product use with future cigarette smoking among youth in the population assessment of tobacco and health (PATH) study, 2013-2015. JAMA pediatrics. 2018;172(2):181-7.

8. Wellman RJ, Dugas EN, Dutczak H, O'Loughlin EK, Datta GD, Lauzon B, et al. Predictors of the onset of cigarette smoking: a systematic review of longitudinal population-based studies in youth. Am J Prev Med. 2016;51(5):767-78.

9. Health UDo, Services H. Reducing the health consequences of smoking: 25 years of progress. A report of the Surgeon General, 1989. DHHS Publication No.(CDC); 1989.

10. Cobb C, Ward KD, Maziak W, Shihadeh AL, Eissenberg T. Waterpipe tobacco smoking: an emerging health crisis in the United States. Am J Health Behav. 2010;34(3):275-85.

11. WHO. Tobacco Free Initiative. https://wwwwhoint/tobacco/en/. 2016.

12. WHO. Tobacco Fact Sheet. world health organisation. 2017.

13. Rozi S, Butt Z, Akhtar S. Demographic influences associated with current smoking status of collage students in Karachi, Pkistan. BMC Public Health. 2007;7:312-20.

14. Organization WH. Tobacco key facts. Retrieved 11 May, 2008. 2008.

15. Eriksen M, Mackay J, Ross H. The tobacco atlas: American cancer society. Inc: Atlanta, GA, USA. 2012.

16. Organization WH. Office for the Western Pacific Smoking Statistics. WHO. 2015;Accessed January 7, 2015.

17. Maziak W. The waterpipe: an emerging global risk for cancer. Cancer epidemiology. 2013;37(1):1-4.

18. Ng M, Freeman MK, Fleming TD, Robinson M, Dwyer-Lindgren L, Thomson B, et al. Smoking prevalence and cigarette consumption in 187 countries, 1980-2012. Jama. 2014;311(2):183-92.

19. Organization WH. WHO report on the global tobacco epidemic, 2017: monitoring tobacco use and prevention policies. World Health Organization; 2017.

20. Warren CW, Jones NR, Asma S. Global youth tobacco surveillance, 2000-2007. 2008.

21. AkI EA, Gunukula SK, Aleem S, Obeid R, Jaoude PA, Honeine R, et al. The prevalence of waterpipe tobacco smoking among the general and specific populations: a systematic review. BMC Public Health. 2011;11(1):244.

22. Elawa F, Warren C, Jones N. Changes in tobacco use among 13-15-year-olds between 1999 and 2007: findings from the Eastern Mediterranean Region. 2010.

23. Primack BA, Shensa A, Kim KH, Carroll MV, Hoban MT, Leino EV, et al. Waterpipe smoking among US university students. Nicotine Tob Res. 2012;15(1):29-35. 
24. Moh'd Al-Mulla A, Abdou Helmy S, Al-Lawati J, Al Nasser S, Ali Abdel Rahman S, Almutawa A, et al. Prevalence of Tobacco Use Among Students Aged 13-15 Years in Health Ministers' Council/Gulf Cooperation Council Member States, 2001-2004. J Sch Health. 2008;78(6):337-43.

25. Ziaaddini $\mathrm{H}$, Meymandi $M$, Zarezadeh $A$. The prevalence and motivation of cigarette smoking among Kerman high school students. Iranian Journal of Psychiatry. 2007;2(1):41-5.

26. Mohammadpoorasl A, Fakhari A, Shamsipour M, Rostami F, Rashidian H. Transitions between the stages of smoking in Iranian adolescents. Preventive medicine. 2011;52(2):136-8.

27. Organisation WH. Age-standardized prevalence of tobacco smoking among persons 15 years and older (\%), by WHO region, 2015. WHO. 2016.

28. Hessami Z, Masjedi MR, Sharifi H, Jamaati H, Emami H. Waterpipe tobacco smoking prevalence and its related factors among Iranian population. Eur Respiratory Soc; 2016.

29. Mohammad-Alizadeh-Charandabi S, Mirghafourvand M, Tavananezhad N, Karkhaneh M. Prevalence of cigarette and water pipe smoking and their predictors among Iranian adolescents. Int J Adolesc Med Health. 2015;27(3):291-8.

30. Kloep M, Güney N, Cok F, Simsek Ö. Motives for risk-taking in adolescence: A cross-cultural study. J Adolesc. 2009;32(1):135-51.

31. Allender J, Spradly B. Community Health Nursing Promotingand Protecting The Public's H ealth. Sixt Edition. Philadelphia Lippincott Willims and Wilkins; 2005.

32. Leventhal $\mathrm{H}$, Cleary PD. The smoking problem: a review of the research and theory in behavioral risk modification. Psychological bulletin. 1980;88(2):370.

33. Mayhew KP, Flay BR, Mott JA. Stages in the development of adolescent smoking. Drug Alcohol Depend. 2000;59:61-81.

34. Paunonen SV. Big Five factors of personality and replicated predictions of behavior. J Personal Soc Psychol. 2003;84(2):411.

35. Vollrath $\mathrm{M}$, Torgersen $\mathrm{S}$. Who takes health risks? A probe into eight personality types. Personality Individ Differ. 2002;32(7):1185-97.

36. Raynor DA, Levine $\mathrm{H}$. Associations between the five-factor model of personality and health behaviors among college students. J Am Coll Health. 2009;58(1):73-82.

37. Carton S, Le Houezec J, Lagrue G, Jouvent R. Relationships between sensation seeking and emotional symptomatology during smoking cessation with nicotine patch therapy. Addict Behav. 2000;25(5):653-62.

38. Jung CG. Psychologische typen: Rascher; 1921.

39. Thompson ER. Development and validation of an international English big-five mini-markers. Personality Individ Differ. 2008;45(6):542-8.

40. Eysenck HJ. A note on 'Smoking, personality and reasons for smoking'. Psychol Med. 1983;13(2):447-8. 
41. Buczkowski K, Basinska M, Ratajska A, Lewandowska K, Luszkiewicz D, Sieminska A. Smoking Status and the Five-Factor Model of Personality: Results of a Cross-Sectional Study Conducted in Poland. Int J Environ Res Public Health. 2017;14(2):126.

42. Zvolensky MJ, Taha F, Bono A, Goodwin RD. Big five personality factors and cigarette smoking: a 10year study among US adults. J Psychiatr Res. 2015;63:91-6.

43. Terracciano A, Costa PT Jr. Smoking and the Five-Factor Model of personality. Addiction. 2004;99(4):472-81.

44. Gau SS-F, Lai M-C, Chiu Y-N, Liu C-T, Lee M-B, Hwu H-G. Individual and family correlates for cigarette smoking among Taiwanese college students. Compr Psychiatr. 2009;50(3):276-85.

45. Yáñez AM, Leiva A, Estela A, Čukić I. The associations of personality traits and parental education with smoking behaviour among adolescents. PloS one. 2017;12(3):e0174211.

46. Von Ah D, Ebert S, Ngamvitroj A, Park N, Kang D-H. Factors related to cigarette smoking initiation and use among college students. Tobacco induced diseases. 2005;3(1):27.

47. Spielberger CD, Reheiser EC, Foreyt JP, Poston WS, Volding DC. Personality determinants of the use of tobacco products. Personality Individ Differ. 2004;36(5):1073-82.

48. Eysenck HJ, Sybil B. An improved short questionnaire for the measurement of extraversion and neuroticism. Life sciences. 1964.

49. Kaviani H, Pournaseh M, Mousavi A. Standardization and validation of the revised Eysenck personality questionnaire in the Iranian population. 2005.

50. Mohammadpoorasl A, Nedjat S, Yazdani K, Fakhari A, Foroushani AR, Fotouhi A. An algorithm of smoking stages assessment in adolescents: A validation study using the latent class analysis model. International journal of preventive medicine. 2013;4(11):1304.

51. Mohammadpoorasl A, Nedjat S, Fakhari A, Yazdani K, Fotouhi A. Predictors of transition in smoking stages in Iranian adolescents: latent transition analysis. 2014.

52. Hampson SE, Goldberg LR, Vogt TM, Dubanoski JP. Forty years on: teachers' assessments of children's personality traits predict self-reported health behaviors and outcomes at midlife. Health psychology. 2006;25(1):57.

53. Yoshimura K. The psychological characteristcs of tobacco dependence in a rural area of japan. Journal of epidemiology. 2000;10(4):271-9.

54. Arai Y, Hosokawa T, Fukao A, Izumi Y, Hisamichi S. Smoking behaviour and personality: a populationbased study in Japan. Addiction. 1997;92(8):1023-33.

55. Malouff JM, Thorsteinsson EB, Schutte NS. The five-factor model of personality and smoking: a meta-analysis. J Drug Educ. 2006;36(1):47-58.

56. Coan RW. Personality variables associated with cigarette smoking. J Personal Soc Psychol. $1973 ; 26(1): 86$.

57. Berger EM. MMPI item differences between smoker and nonsmoker college freshmen males. J Consult Clin Psychol. 1971;36(3):446. 
58. Buczkowski K, Basinska M, Ratajska A, Lewandowska K, Luszkiewicz D, Sieminska A. Smoking status and the five-factor model of personality: Results of a cross-sectional study conducted in Poland. Int J Environ Res Public Health. 2017;14:126.

\section{Tables}

Table 1 Transition matrix in smoking stages with marginal homogeneity test from first phase to second phase of the study in high school students (15-16 years old) in Tabriz 


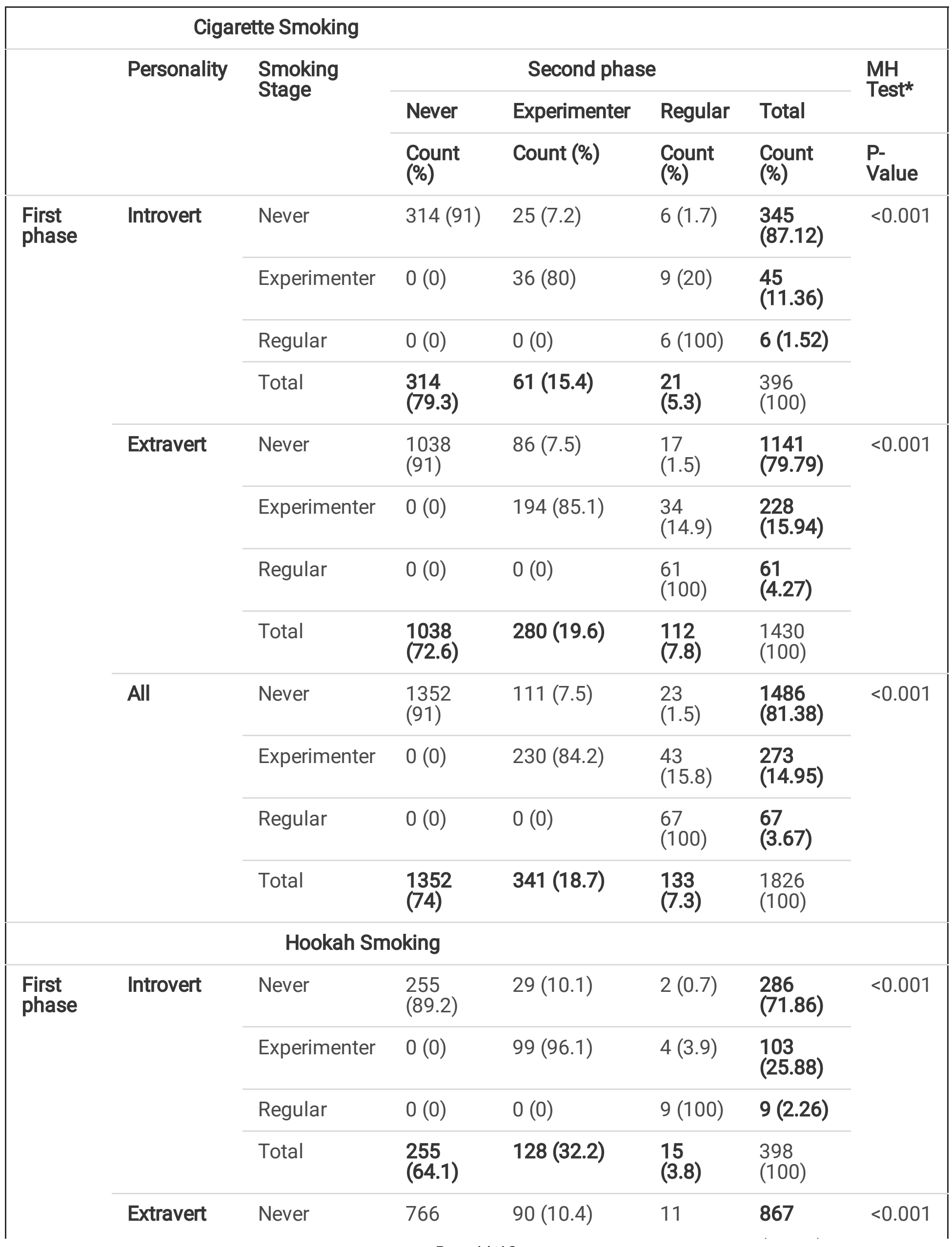




\begin{tabular}{|c|c|c|c|c|c|c|}
\hline & \multicolumn{3}{|c|}{$(88.4)$} & \multirow{2}{*}{$\begin{array}{l}(1.3) \\
47 \\
(9.1)\end{array}$} & \multirow{2}{*}{$\begin{array}{l}(60.42) \\
514 \\
(35.82)\end{array}$} & \\
\hline & Experimenter & $0(0)$ & 467 (90.9) & & & \\
\hline & Regular & $0(0)$ & $0(0)$ & $\begin{array}{l}54 \\
(100)\end{array}$ & $\begin{array}{l}54 \\
(3.76)\end{array}$ & \\
\hline & Total & $\begin{array}{l}766 \\
(53.4)\end{array}$ & $557(38.8)$ & $\begin{array}{l}112 \\
(7.8)\end{array}$ & $\begin{array}{l}1435 \\
(100)\end{array}$ & \\
\hline \multirow[t]{4}{*}{ All } & Never & $\begin{array}{l}1021 \\
(88.6)\end{array}$ & $119(10.3)$ & $\begin{array}{l}13 \\
(1.1)\end{array}$ & $\begin{array}{l}1153 \\
(62.90)\end{array}$ & $<0.001$ \\
\hline & Experimenter & $0(0)$ & 566 (91.7) & $\begin{array}{l}51 \\
(8.3)\end{array}$ & $\begin{array}{l}617 \\
(33.66)\end{array}$ & \\
\hline & Regular & $0(0)$ & $0(0)$ & $\begin{array}{l}63 \\
(100)\end{array}$ & $\begin{array}{l}63 \\
(3.44)\end{array}$ & \\
\hline & Total & $\begin{array}{l}1021 \\
(55.7)\end{array}$ & $685(37.4)$ & $\begin{array}{l}127 \\
(6.9)\end{array}$ & $\begin{array}{l}1833 \\
(100)\end{array}$ & \\
\hline
\end{tabular}

* Marginal Homogeneity Test

Table 2 Generalized Estimating Equation with ordinal logit link to determine the effect of personality and gender on smoking stage transition in the students aged 15 to 16 in Tabriz 


\begin{tabular}{|c|c|c|c|c|c|c|}
\hline \multicolumn{7}{|c|}{ Cigarette Smoking } \\
\hline & & \multirow[t]{2}{*}{$\beta$} & \multirow{2}{*}{$\begin{array}{l}\text { S.E } \\
\text { of } \beta\end{array}$} & \multicolumn{3}{|l|}{$95 \% \mathrm{Cl}$} \\
\hline & & & & Lower & Upper & P-Value \\
\hline \multirow[t]{2}{*}{ Threshold } & $\begin{array}{l}\text { Nonsmoker/(Experimenter and } \\
\text { Regular) }\end{array}$ & 1.607 & 0.1142 & 1.383 & 1.831 & $<0.0001$ \\
\hline & $\begin{array}{l}\text { (Nonsmoker and } \\
\text { Experimenter)/Regular }\end{array}$ & 3.195 & 0.1327 & 2.935 & 3.456 & $<0.0001$ \\
\hline \multirow{2}{*}{$\begin{array}{l}\text { Person } \\
\text { Type }\end{array}$} & Extrovert & 0.448 & 0.1262 & 0.200 & 0.695 & $<0.0001$ \\
\hline & Introvert & Ref & & & & \\
\hline \multirow[t]{2}{*}{ Gender } & Male & 0.922 & 0.1002 & 0.725 & 1.118 & $<0.0001$ \\
\hline & Female & Ref & & & & \\
\hline \multicolumn{7}{|c|}{ Hookah Smoking } \\
\hline \multirow[t]{2}{*}{ Threshold } & $\begin{array}{l}\text { Nonsmoker/(Experimenter and } \\
\text { Regular) }\end{array}$ & 0.787 & 0.0945 & 0.602 & 0.972 & $<0.0001$ \\
\hline & $\begin{array}{l}\text { (Nonsmoker and } \\
\text { Experimenter)/Regular }\end{array}$ & 3.321 & 0.1235 & 3.079 & 3.563 & $<0.0001$ \\
\hline \multirow{2}{*}{$\begin{array}{l}\text { Person } \\
\text { Type }\end{array}$} & Extrovert & 0.519 & 0.1053 & 0.312 & 0.725 & $<0.0001$ \\
\hline & Introvert & Ref & & & & \\
\hline \multirow[t]{2}{*}{ Gender } & Male & 0.661 & .0844 & 0.495 & 0.826 & $<0.0001$ \\
\hline & Female & Ref & & & & \\
\hline
\end{tabular}

